\title{
Knowledge, Oligopoly and Labour in Global Value Chains
}

\author{
Dev Nathan, Society for Labour and Development, India
}

\begin{abstract}
The article explores knowledge in global value chains (GVCs) and its correspondence with the nature of employment in different GVC segments. It starts with the role of knowledge that is protected through intellectual property rights in creating oligopolies in product markets, which are then re-created as oligopolies in the input markets. Knowledge requirements, transmitted through governance relations and the distribution of power within GVCs, lead to the inter-firm distribution of profits within GVCs, and result in differing qualities of employment corresponding to the level of knowledge required in different production segments.
\end{abstract}

\section{KEYWORDS}

global value chains; oligopolies; knowledge; employment quality; labour practices

\section{Introduction}

This article explores the relationships between the structure of global value chains (GVCs) and labour employment in developing countries that are suppliers. This starts with knowledge, usually protected under intellectual property rights (IPRs), creating oligopolies in the product markets in the headquarter economies of lead firms. ${ }^{1}$ In an unequal world - unequal in the distribution of knowledge, incomes and wages - there is the possibility of utilising these differences to increase the profits of oligopolies through the disintegration of production GVCs. GVCs have embedded within them a distribution of knowledge among their different segments - knowledge-intensive segments in pre-and post-production tasks, which are protected under intellectual property rights in lead firms, while the knowledge of production is distributed among many suppliers in developing economies and is not protected under intellectual property rights. The oligopolies on the product market then appear as oligopsonies or oligopolies in input markets, where a few buyers can bargain with many suppliers to the buyers' advantage. In the resulting distribution of value within the value chain, the lead firms earn rents (or super profits), while the suppliers just earn competitive profits.

Before proceeding, a word about terminology. The technical term for a market with few buyers and many suppliers is an oligopsony, while that for a market with few sellers and many buyers is an oligopoly. Not only is oligopsony a somewhat clumsy word, but it is not very commonly used. The term oligopoly can be extended to describe a market where a few players on one side deal with many players on the other side. In this way, we extend the term oligopoly and use it to describe an oligopoly in the product market and also in the input market.

The relationship between lead firms and suppliers has been analysed under the rubric of the governance of value chains (Gereffi, Humphrey and Sturgeon, 2005). The theory of governance of supplier firms divides them into three types of governance, in which I emphasise differentiation

\footnotetext{
1 The terms, "supplier economies" and "headquarter economies" are borrowed from Baldwin (2016).
} 
on the basis of the knowledge level of the tasks to be performed. Suppliers in captive governance are characterised by the low-knowledge level of tasks performed, as seen in the manufacture of garments or shoes. There is an intermediate level of knowledge in supplier firms in modular governance, as seen in automobile and electronics assemblies. Finally, there is a higher level of knowledge in suppliers in relational governance, as seen in the case of information technology (IT) software services. The knowledge levels required and the power of supplier firms have a corresponding effect on the knowledge levels required of the workforce employed in supplier firms and also on whether firms need to retain workers with their embodied knowledge.

Apart from differences in the knowledge levels required in supplier firms, there is a connection between profits and wages. According to Michal Kalecki's (1971) theory of distribution, wages are related to profits; in a GVC, firms with rents will tend to have higher wages than firms with competitive profits. This vertical relation of the inter-firm distribution of profits within a GVC is combined with horizontal relations such as labour market conditions and gender responsibilities to result in wages and other employment conditions in supplier firms such as security of employment. Thus, the knowledge level of tasks carried out by suppliers in GVCs affects the employment of workers in these supplier firms through the knowledge level required of workers, whether suppliers need to retain the embodied knowledge of specific workers, and the powerbased distribution of profits within the GVC.

Keeping in mind the analytical structure just described, this article puts forward the proposition that the knowledge level of production segments carried out by supplier firms would be reflected in the nature of employment of labour. Low-knowledge production segments (captive segments) such as garment and shoe production would hire mainly labour with low wages and low job security. Medium-knowledge segments (modular segments) such as automobile or electronics assemblers would have mainly labour with medium wages and a greater proportion of workers with relatively better job security. High-knowledge segments (relational segments) such as IT services would have labour with high wages and higher proportions of employees with job security.

The article follows this up by looking at empirical data on the relations between the knowledge levels of supplier firms and the quality of employment. This is done in terms of two variables, wages and security of employment. A set of case studies across GVC suppliers, located for the main part in Asian countries, is summarised. The summary shows these case studies to be in line with expectations. Corresponding to the three forms of governance are differences in bargaining power between suppliers and buyers - no or little power in the case of captive segments; some, but not much, power in modular segments; and substantial power in the case of relational segments.

The emphasis is on the role of knowledge, whether protected through IPRs and earning rents or commoditised and earning just competitive profits, in determining the nature of employment in GVC manufacturing or production segments. The resulting inter-firm distribution of rents and profits is reflected in wages and employment conditions. There would be variations around this structure, however. Firm strategies for upgrading could result in higher wages and more secure employment, as firms seek to build firm-level capabilities by retaining skilled labour. Gender relations would affect women's employment possibilities as they are constrained by unpaid care work and child-bearing responsibilities. Labour market conditions of surplus labour, as in most supplier economies, would restrict both increases in wages and improvements in employment conditions. These labour market factors in combination with constraints on supplier profits would constrain the ability to use workers' associational power to increase wages. It is only in the condition where suppliers themselves have some measure of oligopoly power based on reputational assets (Kaplinsky, 2019) that workers could secure some redistribution of higher profits as wages, in the manner of Kalecki's (1971) analysis. 
The analysis in this article does not claim to be a set of hypotheses that have been tested by large-scale, cross-country survey data. Rather, it does provide an analytical structure relating knowledge and knowledge-based power to the quality of employment in global production networks. This analytical structure can be tested and refined through cross-country and crosssegment empirical investigations into global production networks.

Having set out the argument in brief in this introduction, the rest of the article elaborates the argument in the order set out above.

\section{The Double Oligopoly in GVCs}

A GVC has a lead firm, which is usually a brand or a large retailer located in a headquarter economy (Baldwin, 2016) or a developed economy in the Global North, and tiers of suppliers in supplier economies of the Global South. There is a division of tasks between these different tiers of firms. For instance, a brand may keep pre-production tasks (such as design and branding) and postproduction tasks (such as marketing) to itself, while it outsources basic manufacturing to producers and intermediate input suppliers. There is also a distribution of revenue along the chain, which gives a GVC a structure of inequality, making it dependent upon the market structure within which different GVC units operate and on the relation between firms within a GVC.

However, a somewhat neglected dimension of a GVC is that it also involves a division of knowledge in the performance of tasks along the value chain. The knowledge required for the performance of pre-production and post-production is usually retained by the lead firm itself. The carrying out of these tasks becomes the core competence of the lead firm (Prahalad and Hamel, 1990). In their interactions with suppliers, lead firms try to keep suppliers out of the key competences of design and branding, though often unsuccessfully (Kaplinsky, 2019).

The output that lead firms market is protected through IPR regimes, whether of codified knowledge resulting in patents or of tacit knowledge resulting in copyrights and trademarks (Durand and Milberg, 2019). In the garment industry and agro-food industries, IPRs are mainly of the tacit variety, embodied in designs and brands, which have also been called reputational assets (Kaplinsky, 2019). However, reputational assets do depend on some form of knowledge - for instance, that of design, which is then guarded through a trademark. Tacit knowledge can also exist in the production of niche products which may not have patent production. That is the case with the manufacture of denim fabric, which makes it a difficult-to-enter segment, giving the denim producers, who tend to be large, some form of market power.

The consequence of such IPRs is that intellectual oligopoly capitalism has become the dominant form of contemporary capitalism - if we modify the term used by Ugo Pagano (2014), who calls it intellectual monopoly capitalism. There are a few dominant brands or companies in each sector; for example, now there are Apple, Samsung, Huawei and three other Chinese brands in the smartphone market. This is a form of oligopoly created through technical IPRs. There are also oligopolies created through brands (that is, reputational assets). For instance, Mars, Mondelez, Nestle, Ferrero, Hershey and Lindt together account for 60 per cent of the global market for chocolates; Starbucks, Dunkin and JAB together have 78 per cent of the chain coffee stores in the United States (US) (Statistica, 2019, 2020). However, the oligopolies are subject to erosion, as other firms copy or otherwise develop the knowledge required (Kaplinsky, 2019).

In the contemporary world, where the knowledge of manufacturing is spread quite widely across the world, we get the second condition for the creation of a GVC. This is the separation of the task of conception from that of execution. The spread of execution or production capabilities 
means that the separation of conception from execution is not an intra-firm division of labour between management and labour, as discussed by Pagano, but an extension of Adam Smith's intrafirm division of labour to the inter-firm and even inter-country level.

Since the capabilities required for production are quite well distributed around the world, there are many suppliers, in contrast to the oligopoly of a few lead firms as buyers. The suppliers usually function in a competitive market, with competition both within a country and between countries. The global garment value chain is an iconic example of the GVC relationship, with oligopolistic lead firms on one side and the many garment suppliers on the other side. However, as we will see below, the numbers of suppliers vary with the ease or difficulty of acquiring the knowledge and capabilities required to perform the necessary tasks in a segment. This is also likely to modify power relations between oligopolistic buyers and suppliers to such an extent that some suppliers may themselves be (or become) oligopolistic, and there may be a shift in bargaining power and the distribution of value within the GVC in favour of oligopolistic suppliers. These variations in the balance of power within the value chain will be analysed later.

Thus, the GVC is based on a double oligopoly - that of lead firms in both product and input markets. However, the two oligopolies are connected. Those with an oligopoly in the product market appear on the global stage as input buyers. The few output sellers become the few input buyers further down the chain. Furthermore, it is the oligopoly on the product side, protected by global IPR regulations through the 1994 Agreement on Trade-Related Aspects of Intellectual Property Rights (TRIPS), which allows these product oligopolies to appear as oligopolies on the input side involving the many suppliers. The crucial factor is the oligopoly created or supported by IPR protection. Thus, privatised knowledge, whether in the form of the explicit knowledge of patents or the tacit knowledge of copyrights and trademarks, is the critical factor enabling the creation of a GVC, with a separation between conception and execution.

The specific question addressed in this article is: What is the impact of this GVC structure on labour? This study deals with this question at two levels. First, it looks at differences in the employment of labour at the inter-country level, specifically in the nature of differences in labour employed in the sites of conception and execution. Second, it examines the employment of labour at the suppliers' end with differences in the intra-firm distribution of labour, based on the nature of tasks in production. We will now deal briefly with the inter-country differences.

The division of knowledge in a GVC also results in knowledge-intensive segments, requiring more educated and high-skilled labour than production segments. For instance, the information communication technology (ICT) segments in 2009 in the United States and China show exactly the opposite composition of their respective workforces - the proportion of high-skilled labour was about 45 per cent in the US industry, while it was just 10 per cent in China; on the other hand, the proportion of low-skilled labour in the ICT industry was just 10 per cent in the United States, while it was 45 per cent in China (Degain, Meng and Wang, 2017: 58-59; see also Table 1 below).

In industry as a whole, the proportion of low-skilled labour in 2009 was around 10 per cent in the United States, while it was 65 per cent in China (Table 1). The compensation per hour also varied between these skill levels, with US remuneration ranging between three times that of China for low-skill workers to more than four times for high-skill workers in the ICT sector (Degain et al., 2017: 59-59). This is an aspect of global inequality embedded in GVCs into which we do not go any further in this article, except to point out that it is related to the double oligopoly - oligopoly profits in both product and input markets. This skews the distribution of profits in the value chains and provides the condition for labour performing similar tasks to be very differently remunerated in headquarter and supplier firms. 
Table 1:

Percentage distribution of skilled labour in the United States and China, 1995-2009

\begin{tabular}{|l|l|c|c|c|}
\hline & & Low-Skill & Medium-Skill & High-Skill \\
\hline All Industries & United States & 10 & 60 & 30 \\
\hline & China & 65 & 30 & 5 \\
\hline ICT & United States & 10 & 45 & 45 \\
\hline & China & 45 & 45 & 10 \\
\hline Construction & United States & 20 & 70 & 10 \\
\hline & China & 55 & 40 & 5 \\
\hline
\end{tabular}

Source: Approximations from Tables 2.21 and 2.22 in Degain et al., (2017: 58-59).

\section{Knowledge in Production Segments}

How, do relations between lead and supplier firms, or vertical relations in GVSs (Neilson and Pritchard, 2009) affect employment conditions in supplier firms? Pagano (2014: 1421-1422) argues that "the skills of workers are likely to be properly developed only when a secure legal access to property rights on disembodied knowledge is available". That is, "embodied knowledge (i.e. the knowledge that cannot be separated from the worker's capabilities) is strictly related to that of disembodied knowledge" (Pagano, 2014: 1420). This would mean that workers in lead firms with IPRs are more likely to have strong security of employment, as lead firms attempt to retain the embodied knowledge of workers. On the other hand, in supplier firms that do not have protection through intellectual property rights, there would not be a similar need to retain the relatively easily replaceable embodied knowledge of its workers.

This is at a broad level. However, there are a number of aspects to these vertical relations. One is the distribution of value between lead firms and suppliers within the chain. Other aspects relate to the business practices of lead firms in GVCs and their impacts on employment conditions (wages, security of employment, etc.) in supplier firms.

Vertical relations relate to the distribution of market power within GVCs: oligopolistic in the case of lead firms, and competitive in the case of suppliers. This results in a distribution of value within the GVC - super-profits or rents to the lead firms and only competitive profits to the suppliers (Nathan and Sarkar, 2011). Pre- and post-production tasks capture a major share of the value, compared to manufacturing tasks. (See the depiction by Stan Shih [2010] of the famous GVC smiley curve).

Carrying out tasks, however, is based on the possession of the required knowledge and capabilities. Thus, the distribution of tasks can also be termed the distribution of knowledge within a GVC. In Lakhani, Kuruvilla and Avgar (2013) the knowledge in a production segment is characterised by the manner in which it is coordinated or governed. The different forms of governance in Gereffi et al. (2005) can be used to characterise knowledge in the production segment.

\section{Governance and Distribution of Value within GVCs}

How does the distribution of income in a GVC vary with the governance type? Income distribution can be examined in the cases of captive, modular and relational governance. Hierarchical governance should not be considered since the distribution of revenues within the branches of a firm is a matter of bureaucratic decision-making within the firm, and is often based on tax 
considerations. Furthermore, we need not take up market linkages separately. Instead, the analysis of captive, modular, and relational governance structures can be extended to the distribution of revenues for similar products in market linkages.

To illustrate the different forms of market linkages, consider software and other office inputs, such as stationery. The software for operating personal computers (PCs) and office stationery are both usually bought through market linkages. However, a PC's operating software, being a knowledge-intensive and complex product with intellectual property protection, has allowed Microsoft to have a great deal of monopolistic authority, which has enabled it to become one of the largest companies in the world. On the other hand, supplies of stationery and related office inputs are commodified and undifferentiated products, thus not giving their suppliers much pricing power in the market. Therefore, market-linked governance is not a homogeneous category in terms of its implications for inequality. Some products may have monopoly power while others may not, with different implications for inequality within the value chain.

\section{Income distribution under captive governance}

In captive governance, since the knowledge required for production is relatively easily acquired, there are many suppliers relative to the number of buyers. This oligopolistic market structure gives the buyers much more power when bargaining with suppliers. It is regularly reported by suppliers in India, Bangladesh and many other countries in Asia that brands are able to squeeze supplier prices. These brands now insist on open costing, where every item of cost is brought into the bargaining structure. Of course, they are able to threaten to take their business to some other country. Suppliers in India point out that they are often told by buyers that suppliers in Bangladesh or Vietnam are offering a particular price, and asked whether they (the Indian suppliers) could match it. The result is that suppliers' margins are constantly shaved, often resulting in them reducing wage costs by forcing workers to perform low-paid overtime work.

As an example of the low-income share of suppliers, Table 2 summarises calculations for garments from one supplier in India.

Table 2: Retail prices and FOB shares in 2016

\begin{tabular}{|l|c|c|c|}
\hline & $\begin{array}{c}\text { US Retail Prices } \\
\text { (US Dollars) }\end{array}$ & $\begin{array}{c}\text { Indian FOB* Prices } \\
\text { (US Dollars) }\end{array}$ & $\begin{array}{c}\text { Indian Share of } \\
\text { Retail Price (\%) }\end{array}$ \\
\hline Ladies' top & 25 & 8.50 & 34.0 \\
\hline Ladies' dress & 34 & 11.00 & 32.3 \\
\hline Kids' top & 20 & 5.50 & 27.5 \\
\hline Kids' dress & 25 & 6.50 & 26.0 \\
\hline Ladies' skirt & 34 & 8.00 & 23.5 \\
\hline
\end{tabular}

Source: Author's fieldwork.

* FOB $=$ Free on Board. A common term in procurement and shipping, it indicates that the price includes the cost of the goods, their transportation to the point of shipment and loading costs. Thereafter, any additional costs, such as shipping and insurance, are the responsibility of the buyer.

These are for garments with embellishments, for which the FOB share of the retail price is higher than that for basics such as T-shirts, where the FOB price would be around 10 per cent of the retail price (Nathan et al., 2020). A calculation for men's polo-necked shirts from Bangladesh in 2006 showed the FOB price as just 10.86 per cent of the US retail price; the FOB share went up to 25 per cent in the case of five-pocket jeans (Miller, 2013). Both material inputs and the complexity of the product have an effect on the suppliers' share of the retail price. 
The higher share of retail prices may reflect the higher costs of distribution or higher profits, or a combination of the two. However, the skewed distribution of income within the value chain results in high profits for global apparel brands. Liz Clairborne or Phillips-Van Heusen had gross profit margins of around 35 per cent in 1991, WalMart had a gross profit rate of above 20 per cent in the same year, while at the upper end, Woolworths had a gross profit rate of above 32 per cent (Applebaum and Gereffi, 1994). Looking at the current situation, in 2017 Ralph Lauren, Gap and Levis had gross profit rates of 57 per cent, 37 per cent and 52 per cent respectively (csimarket.com, 2019). This should be contrasted with the 10 per cent or lower profit rates of Indian garment suppliers (Nathan et al., 2020).

The results discussed in the preceding paragraph from a study of supplier-buyer relations in the Indian apparel industry are corroborated by a study of Bangladesh garment GVCs (Anner, 2019). The Bangladesh study reports that, as a result of the pricing squeeze, supplier profits declined by 13.3 per cent from 2011 to 2016. In Cambodia, too, a decline in supplier profits is being reported, which is contributing to the raising of workers' production targets (CENTRAL, personal communication).

Thus, in captive governance, using the apparel value chain as an example, there is a skewed distribution of income within the value chain, resulting in higher profits for global apparel brands and lower, competitive profits for suppliers.

\section{Income distribution under modular governance}

In modular governance, the knowledge required for production is codified, though it is more complex than in the case of captive governance. As a result, there tend to be fewer suppliers than in the case of captive governance. Nevertheless, the shares of producers are quite low, as seen in one of the major cases of modular production in GVCs - that of consumer electronics.

A calculation along the iPhone value chain is a well-known example of the low share of the assembler and the high share of Apple in the distribution of income along the value chain. While Apple captured an extraordinary 58.5 per cent of the price of an iPhone; component suppliers received only 14.3 per cent, while the Chinese firm assembling the iPhone secured just 1.8 per cent of the value chain's income (Chan, Pun and Selden, 2016).

The distributions of income along the value chain discussed here have translated into inequalities in the margins of different actors in these value chains. The operating margins of major electronics contract manufacturers like Hon Hai (Foxconn), Flex and Jabil Circuit were as low as 3.53 per cent, 1.84 per cent, and 2.20 per cent respectively in 2015 (Raj-Reichert, 2018: 25). Gross profit margins were higher - between 6 and 10 per cent. Volumes or total revenues, however, are high, enabling a reasonably high total profit, but the competitive market in contract manufacturing and the threat of losing market share to low-cost competitors keeps margins low (Raj-Reichert, 2018: 37-38). The effect of razor-thin profit margins is that medium-sized firms cannot invest in research and development (R\&D) (Ernst, 2012); but if firms are large in terms of size, then high volumes would enable them to undertake substantial investments in R\&D.

At the other end are the gross profit margins of the lead firms or brands. For Apple, the gross profit margin went up from around 20 per cent in 1997 to almost 40 per cent in 2015, while that for Dell hovered around 20 per cent in the same period. HP's profit margin went down from about 28 per cent in 1997 to about 18 per cent in 2015 (Raj-Reichert, 2018: 38-39). HP was functioning in an increasingly commoditised low-end PC market, while Apple operated in a high-end, differentiated market, commanding a premium over all other smartphone makers.

To summarise, in modular governance there tends to be a high level of inequality in income shares, with low margins for contract manufacturers and high margins for leading brands. In the 
case of the electronics industry, though, there is a sharp difference in income shares between brands, with Apple commanding a premium price and clearly ahead of the rest.

\section{Income distribution under relational governance}

In relational governance, there is close and frequent interaction between the buyer and the producer or supplier. IT services are a good example of the frequent interactions involving design, architecture, programming, testing and initialising services. Indian IT services have tended to belong to the middle or lower segments in the IT value chain, consisting substantially of programming, testing, checking and maintenance services. However, even in these services, there is frequent interaction while providing the services, and the buyer is dependent on the quality of the services supplied. Within the group of fifty or so Indian IT service providers having the highest quality certification, a few have built a reputation for quality and reliability, which enables them to charge a premium rate for their services. Indian IT majors such as TCS and Infosys include a margin of around 25 per cent in the price at which they offer their services. IT firms with lesser reputations such as HCL or Tech Mahindra charge a slightly lower rate (Sachitanand, 2018). These high margins show that IT software service suppliers have some market power, which is likely due to their reputational assets and tacit knowledge.

\section{Recapping governance and revenue patterns}

It is interesting to note that supplier pricing systems in apparel and IT services have moved in opposite directions. During fieldwork undertaken by the author in 2017 and 2018, apparel manufacturers in and around Delhi pointed out that during the period of the Multi-Fibre Agreement (MFA), quotas were given to each exporting country, so suppliers were able to quote lump-sum prices with margins of around 25 per cent. When the MFA ended, there was intense competition among Asian supplier firms and countries. Margins went down. After the Great Recession of 2008, supplier margins went down even further. With intense competition among firms in different countries, buyers were able to push down prices till margins were less than 10 per cent.

In the IT industry, on the other hand, Indian suppliers initially costed on the basis of personday and equipment costs, with a margin added to this cost. The founder of Infosys, Narayana Murthy (2009), gives a poignant description of how big clients utilised competition among suppliers to push down prices. However, as they established their reputation for outsourced services in the world market, the Indian IT service suppliers shifted to quoting lump-sum prices with much higher margins.

To sum up, while apparel manufacturers and electronics contract manufacturers secure 10 per cent or lower margins, Indian IT service suppliers, with margins between 15 and 25 per cent, are somewhere in the middle, while monopoly profits or rents of around 50 per cent are secured by major global brands such as Apple in electronics or Levi's and Ralph Lauren in apparel.

Having seen the connection between governance and revenues within GVCs, we turn to the impact of these relations on wages and the conditions of employment of labour in supplier firms.

\section{Vertical Relations: Supplier Prices and Wages}

The distribution of value within a GVC affects wages, as predicted by Kalecki's (1971) theory of distribution, where wages are based on the degree of monopoly within which a firm operates. A number of studies support the Kalecki proposition that workers' wages are positively connected 
to the rents earned by the firms. Empirical studies in countries like the United States ((Mishel, 1986), Belgium (Dobbelaere, 2005) and India (Pal and Rathore, 2014) support Kalecki's assertion that there is a link between high mark-ups and the demand for higher wages by unions.

The connection between a firm's ability to mark up its prices and demands for higher wages is fairly straightforward. Firms that can mark up prices are able to cover an increase in costs due to higher wages. With their mark-up power, they operate in a cost-plus product market. In such a situation, workers' demands for higher wages are likely to be conceded. In situations where firms have to regard prices as unchangeable, such as in a competitive market situation, they cannot cover increases in costs through a mark-up. Where industry-level bargaining does not take place, suppliers in a competitive market would resist an increase in wages.

Rather than being just a derivative relation between profits and wages, there can also be a twoway relationship. As argued in the literature, there can be a co-determination of wages and profits (Ichinowski and Shaw, 2003). Paying higher wages and generally better conditions of work can improve firm performance. A study of the garment industry in India found just such a relationship (Nathan et al., 2020). However, there is a caveat. Due to the oligopoly situation, the benefits of increased productivity of suppliers were mainly captured by buyers. The margins of more productive suppliers were not different from those of other, less productive suppliers - a median profit rate of 10 per cent for the former as against 9 per cent for the latter. The benefit that the more productive suppliers secured was that of larger orders and, as a result, faster firm growth. Profits increased but margins did not.

Other vertical relations that affect labour are the manner in which buyers cost labour, and the short (and falling) lead times. Given competition among suppliers, lead firms cost labour at the level of prevailing national minimum wages, which are usually far below living wages (Bhattacharjee and Roy, 2016).

Supplier firms and their workers, however, are situated not only in vertical GVC relations with lead firms, but also exist or are embedded in social and economic relations within their own supplier countries. These are power and market relations between employers, employees and states in supplier countries. We now turn to the role of these national institutional factors, or horizontal relations, in influencing employment outcomes in GVC supplier firms and countries.

\section{Horizontal Relations}

Horizontal relations in GVCs are constituted by the institutional factors in supplier countries and also by their labour market conditions.

National institutional factors in supplying countries are not the creation of GVC lead firms. Child labour, for instance, existed before the initiation of GVC-based production and continues even in the production of non-tradable products such as in road-side eateries or auto-repair workshops in India and other countries. Similarly, systems of forced or bonded labour are both older than GVC-related production and exist quite independently of GVCs.

However, what is true is that GVC production has utilised both child labour and other forms of bonded or forced labour. As Allain et al. (2013) argue, child labour and forced labour have to be understood as part of the business practices or business strategies of lead firms. Some notorious examples of conflict-related forced labour are those used in the mining of diamonds and of coltan - a rare metallic ore used in the production of electronics and mined from civil-war-torn areas of the Congo (Nathan and Sarkar, 2010).

Factors that impact wages and employment conditions in developing countries include local 
laws and the local labour market. Where laws allow the employment of non-standard employees without social security (for example, the contract labour system), then there could be the use of such labour even without or beyond any requirement for flexible employment numbers.

The state of the labour market is obviously of importance in matters like wage-setting. With developing countries going through the transformation of shifting surplus labour from agriculture into manufacture and services, there is an "unlimited" supply of workers available at or just above the existing rural wage (Lewis, 1954). As long as this surplus labour exists, wages in GVC-related manufacturing would not face the labour markets' pressure for upward revision. However, with the passing of this transition, as is occurring in China (Fang and Wang, 2010), there would be a general upward pressure on wages. At the same time, there might also be specific labour shortages for particular types of workers.

Gender relations and the division of labour within households affect the manner in which women interact with the labour market., The absence of institutionalised childcare might lead to women leaving the labour force during child-bearing and childcaring years and thus losing seniority. It might also lead to women not being able to accept promotions linked to transfers. In one way or the other, unpaid and unshared care work could lead to women workers being unable to achieve the potential employment quality they are capable of based on their educational and knowledge endowments.

\section{Labour Outcomes: Knowledge and Employment Quality}

We now return to the GVC distribution of tasks. Pre-production (design), production (manufacture) and post-production (branding and marketing) is a coarse-grained division of tasks within a value chain. How does a GVC's distribution of tasks relate to employment conditions? The level of analysis has to shift from that of the firm to that of workers or employees. In such an analysis we need to move from the coarse-grained division of labour between GVC segments to the fine-grained division of labour in tasks performed by workers and the capabilities required for their performance.

Tasks require workers with certain capability levels, which are based on the workers' knowledge levels. Employment has many features - wages, security and so on. One can make an index of employment quality. At present, however, since the object of this exercise is to derive a few readily analysable categories, we stick to a unidimensional measure of job quality - that is, employment security. ${ }^{2}$ What are presented below are stylised facts (or broad generalisations) on knowledge levels of supplier firms and employment quality.

Behind Table 3 below lies a relationship that we do not keep repeating - that the knowledge level of a GVC supplier firm is related to the power that the supplier has in the GVC chain, and, in turn, in the profits that a supplier can earn. Thus, low-knowledge tasks in captive governance carry with them no power in GVC bargaining and provide only minimal competitive profits. Medium-knowledge tasks in modular governance without many competing suppliers give some bargaining power and a medium level of profit. High-knowledge segments in relational governance provide some price-setting power and thus lead to higher profits. These background relations should be kept in mind when reading the analysis of the connection knowledge levels of GVC supplier segments and the quality of employment.

The relationship put forward in this article is not between employment equity and knowledge

2 This section is developed from Nathan (2016). 
as such, but between firms' knowledge reflected in bargaining power and employment quality. The intervening factor of bargaining power is taken for granted in order to simplify the statements. Again, the connection made is not between the knowledge that workers possess leading to employment quality, though that relationship may also exist; rather the connection is between quality of employment and the knowledge level of GVC supplier firms' production segments, through the influence on bargaining power in GVCs and profits. In a sense, this is the application to GVCs of Kalecki's (1971) theory of the degree of monopoly determining the distribution between profits and wages.

For both the security or quality of employment and the knowledge base of workers, we consider three levels - high, moderate and low. This gives us nine possible combinations of the two variables - knowledge and quality of employment - with three levels for each of the variables.

Table 3: Knowledge levels and job quality

\begin{tabular}{|c|c|c|c|}
\hline High (3) & $\begin{array}{l}\text { High knowledge; } \\
\text { Low job quality } \\
{[\mathrm{G}]}\end{array}$ & $\begin{array}{l}\text { High knowledge; } \\
\text { Moderate job } \\
\text { quality } \\
{[\mathrm{H}]}\end{array}$ & $\begin{array}{l}\text { High } \\
\text { knowledge; } \\
\text { High job } \\
\text { quality } \\
\text { [I] }\end{array}$ \\
\hline Moderate (2) & $\begin{array}{l}\text { Moderate } \\
\text { knowledge; } \\
\text { Low job quality } \\
\text { [D] }\end{array}$ & $\begin{array}{l}\text { Moderate } \\
\text { knowledge: } \\
\text { Moderate job } \\
\text { quality } \\
\text { [E] }\end{array}$ & $\begin{array}{l}\text { Moderate } \\
\text { knowledge; } \\
\text { High job quality } \\
{[\mathrm{F}]}\end{array}$ \\
\hline Low (1) & $\begin{array}{l}\text { Low knowledge; } \\
\text { Low job quality } \\
\text { [A] }\end{array}$ & $\begin{array}{l}\text { Low knowledge; } \\
\text { Moderate job } \\
\text { quality } \\
\text { [B] }\end{array}$ & $\begin{array}{l}\text { Low knowledge; } \\
\text { High job quality } \\
{[\mathrm{C}]}\end{array}$ \\
\hline $\begin{array}{l}\text { Knowledge } \\
\text { Level (K) of } \\
\text { Tasks / } \\
\text { Job Quality (Q) }\end{array}$ & Low (1) & Moderate (2) & High (3) \\
\hline
\end{tabular}

Source: Created by author

The $3 \times 3$ matrix in Table 3 is a framework through which the links between knowledge and job quality can be classified. However, we could develop a theory or hypothesis to be applied to this framework. The simplest one is that the level of job quality is determined by the knowledge level of a task performed in a GVC segment. This would give us the cells in bold along the diagonal GVC suppliers performing low-knowledge tasks lead to a low-quality employment structure; medium-knowledge tasks lead to a moderate-quality employment structure; while high-knowledge or knowledge-intensive tasks lead to a high-quality employment structure. The segmentation of the labour market by job quality is, in this analysis, related to the knowledge level required in order to perform the tasks assigned to the GVC supplier.

It should be noted that the term "employment structure" does not imply that all jobs in a GVC supplier would be of the same low, medium or high quality. Instead, there would be proportionately more jobs of each category in the relevant employment structure. In fact, any GVC 
supplier would not only offer jobs belonging to just one knowledge level and/or quality. In garment production, for instance, there are standard assembly-line tailors, moderate-knowledge sample tailors and high-knowledge design tailors. Such a distribution of workers at different knowledge levels can be represented by the diagonal in Table 3, thus illustrating the link between knowledge and employment quality within a single firm rather than between GVC supplier firms.

The analytical scheme described here, relating the knowledge level of the GVC segment, via bargaining power in GVCs, with employment quality, should help in bringing both order and an awareness of causative factors into the discussions of empirical case studies. The quality of employment in GVC segments can be categorised as low, medium or high and compared to the knowledge level of production in that GVC segment. Policy and institutional interventions could be brought into the picture to move employment outcomes positively in a rightward or upward direction.

To judge whether this analytical scheme relates to empirical observations, we look at the connection between the analytical scheme and empirical investigations through a summary of numerous case studies in terms of the employment characteristics of these three types of GVC relations: those in captive and low-knowledge segments, in modular and intermediate-knowledge segments, and in relational and high-knowledge segments.

\section{Empirical Investigations: Summarising Case Studies}

The analysis set down in the preceding paragraphs was in fact inferred from a summary of multisector, multi-country case studies, mainly in the collection Labour in Global Value Chains in Asia (Nathan, Tewari and Sarkar, 2016). The nineteen case studies in that book covered garments, agrifood products, tourism, leather products, mobile phones, telecom services, automobiles, call centres and IT software services. These case studies, and some others from the Capturing the Gains research programme, are summarised below to show the links between knowledge levels of suppler firms and employment conditions.

GVCs of low-knowledge segments such as garment and shoe manufacture, agri-food production and tourism services all provide employment with low levels of security and high levels of supply through brokers, along with the hyper-mobility of workers. Wages are low, at or around the national minimum wage.

Work in the low-knowledge segments is often outsourced from the supplier factories to both "shadow factories", with even worse conditions of employment, and to home-workers. There are a high proportion of women in these segments, who particularly dominate the home-worker segment. Agricultural production in GVCs, such as those of cocoa (Barrientos, 2014) and fresh vegetables and fruit (Evers, Amoding and Krishnan, 2014) is often carried out on small farms, subsuming within them the labour of women and men as self-employed workers for GVCs.

Modular-governance GVCs, such as electronics assembly or automobile manufacture, require knowledge that is of moderate complexity but high codifiability. These GVC segments also require workers with a reasonable level of education, instead of the merely literate workers required in garment manufacture or much of agri-processing. Orders are volatile, however, particularly in electronics, and this leads to substantial numbers of temporary and agency workers, low stability of employment in some countries and high levels of overtime in others (Samel, 2012 [Malaysia]; Holdcroft, 2015 [Thailand]; Chan et al., 2016 [China]). Supervision is of the Taylorist variety, with the pace of work set by the speed of assembly lines.

Much work in back-office services, such as call centres handling customer care, requires a 
knowledge of English or some other European language. While the educational requirements go up in comparison to electronics or automobile assembly, that does not make for more complex knowledge requirements. New forms of electronic monitoring of work, such as measuring the time spent on performing a task, have led to methods of surveillance that are called digital Taylorist forms of office work (Noronha and D'Cruz, 2016). Modular governance GVC segments provide an intermediate quality of employment.

In relational-governance GVCs, such as IT software services, the knowledge requirements are more complex, involving some of the design in addition to the development and maintenance of IT systems. However, even in this, there is a division of labour, with design often being undertaken in headquarter economies and the development and maintenance of the systems being undertaken in developing countries. Indian IT firms, for instance, are concentrated in the middle- to lowercomplexity sections; though they are moving into design and full-package supply (Sarkar, Mehta and Nathan, 2013; Ahmed, 2018).

In the IT software GVC segments, workers are required to have a high level of knowledge and employment is secure, but the drive to reduce costs makes employees vulnerable to "bell curve" methods of dismissal, where a certain percentage of assessed employees who are at the bottom of the curve are dismissed each year. The earnings, however, are higher than for employees of comparable qualifications in other sectors (Sarkar and Mehta, 2016). This is made possible by the higher margins (from 17 per cent to 25 per cent) in the IT software services industry. In the manner of Kalecki's (1971) hypothesis, higher rates of profit in IT services enable and can lead to higher wages. At a broad level, the case study data falls into three knowledge levels of supplier firms and employment categories - low-knowledge supplier firms with poor employment quality; medium-knowledge supplier firms with intermediate employment quality and high-knowledge firms with high employment quality.

\section{Interaction with Other Factors}

How do additional factors - other than the knowledge level of the task distribution in GVC supplier firms - influence job outcomes in terms of job quality? The relationships between firms' knowledge types and job quality can be modified by firm strategy, such as building capabilities in order to move into higher-income activities (Nathan, Saripalle and Gurunathan, 2016). For such upgrading, a supplier would need to retain more of the knowledge embodied in workers and thus provide more secure employment to them.

When profits remain low and orders unstable, then the poor quality of jobs in low-knowledge tasks is reinforced. However, the redistribution of rents to supplier factories in a GVC or the stability of orders could together enable higher wages and more secure jobs.

The relationship between knowledge levels of supplier firms and employment is also moderated by the context within which firms function, such as national labour market regulatory institutions and the state of the labour market. National institutional factors, particularly labour laws, obviously influence the nature of jobs. To take an example from China, the Contract Labour Law increased security of employment for workers in general (Lan and Pickles 2011). China also has a regulation that restricts flexible labour to less than 10 per cent of the total workforce of an enterprise. There may well be breaches of these laws, but their existence changes the context in which employment relations are decided.

Similarly, the state of the labour market influences both wages and the security of jobs. At the national level (in developing countries) the overall scarcity of labour can push up wages, as has 
happened in China, but even local scarcity, increased by language problems, can also lead employers to offer more secure jobs.

On the other hand, gender-based domestic responsibilities borne primarily by women negatively affect their participation in the labour market. The need to combine domestic responsibilities - especially childcare - with paid work can force women to choose insecure and low-paid but flexible work from home rather than more secure and better-paid but inflexibly scheduled work in factories (Pani and Singh, 2014). Women in IT software service suppliers have been seen to be far less represented in higher levels of the workforce. This has been related to the inability of women to accept transfer-linked promotions (Kelkar, Shrestha and Veena, 2002). This would reduce the quality of women workers' jobs below that predicted by their supplier firms' knowledge levels.

Workers' associational power (Silver, 2003) can also influence labour market outcomes. This, however, would be limited by the knowledge level of tasks carried out by supplier firms. Thus, the possibility of improvements in labour outcomes, particularly wages, is restricted by the position of the supplier firm within the GVC. Suppliers in easily-acquired knowledge segments of commoditised production would earn competitive profits and this would restrict the wages that could be paid. Only suppliers that establish reputational assets, as is the case with the major Indian IT service suppliers who are able to set margins of up to 25 per cent, as mentioned above, would be able to go above market wages. Associational power would influence wages, but there is a limit to what can be achieved, a limit set by the generally low, competitive profits earned by supplier firms in GVC segments that perform low-knowledge tasks.

\section{Knowledge and Power}

This article is predicated on the role of knowledge in both driving the distribution of income within GVCs and in the nature of employment in GVC segments. Knowledge, however, does not on its own or directly produce these effects. Knowledge works through power in market or bargaining relationships within the GVCs. Knowledge is the base of power in this analysis, but unless knowledge can be used to affect bargaining relationships, it would not produce results either in changing the distribution of income or in the nature of employment.

The first manifestation of knowledge as the base of power was seen, in this article, in the oligopolistic nature of lead or headquarter firms in GVCs. Oligopoly can also be termed the "degree of monopoly", to use Kalecki's (1971) phrase. Technical knowledge protected through IPRs, reputational assets protected through brands and trademarks, or through the possession of hard-to-acquire tacit knowledge - all these create oligopolies in the product market. These same oligopolies reappear as buyers of inputs, including fully manufactured products. Faced with many suppliers, the oligopolistic buyers are able to confine suppliers to the competitive margins. It is only when suppliers are able to protect the knowledge in their supply of inputs as chokepoint technologies, whether sophisticated components in the automotive industry or platform technologies, such as computer operating systems, that the bargaining power of suppliers shifts in favour of these IPR-protected suppliers. Or, they may be suppliers of niche inputs with complex and tacit knowledge requirements, as in the case of denim producers. The third case of suppliers being able to increase their margins is in the case of suppliers of IT services who have acquired reputational assets. In each case, however, it is only when knowledge can result in greater bargaining power that it results in higher margins or a higher rate of profit.

The next level of analysis is that of the effect of knowledge as power through profit rates to 
employment conditions, including wages. In straightforward Kaleckian terms, the extent of oligopoly or the degree of monopoly has an effect on profit rates, being higher with a higher degree of monopoly. This rate of profit affects the intra-firm bargaining power of workers. Where the supplier firms' margins are higher, in suppliers with some IPR protection as well as reputational or niche knowledge assets, then workers can also bargain for higher than market wages. As an employee of a large niche supplier of denim is reported to have said, "Smaller garment companies I have worked for never had the profits for us to demand higher wages... Even if Arvind lie to us we can find out the truth easily because it is a big public company" (Kumar, 2020: 134).

This paper stops at analysing the relationship between supplier firm knowledge, working through power in bargaining to produce differences in rates of profit, which, in turn, affect workers' bargaining power within suppliers. To continue the analysis, one would have to identify the conditions under which workers' embodied knowledge increases their bargaining power vis-à-vis supplier firms of different types. But that is another story, to be taken up in another article.

\section{Conclusions}

In this article it has been argued that the knowledge level of tasks performed in GVC supplier firms substantially determines the quality of employment in supplier firms in the Global South, because it affects the bargaining power of supplier firms. A low-knowledge requirement of tasks performed by supplier firms gives them little bargaining power and results in low, competitive profits that set limits to the possibility of increasing wages and improving the quality of employment. A mediumknowledge requirement gives supplier firms some, but not much, bargaining power and an intermediate quality of employment. Generally, it is only in cases where supplier firms have acquired IPR-protected or reputational assets, and consequently increased their bargaining power, reflected in higher profit rates, that employment quality improves along with the increase in profits.

\section{REFERENCES}

Ahmed, Neetu (2018) Strategic Change in Indian IT Majors: A Challenge. In Development with Global Value Chains: Upgrading and Innovation in Asia, edited by Dev Nathan, Meenu Tewari and Sandip Sarkar. Cambridge: Cambridge University Press.

Allain, J., A. Crane, G. LeBaron and L. Behbahani (2013) Forced Labour's Business Models and Supply Chains. jrf.org.uk. https://www.jrf.org.uk/report/forced-labour $\% \mathrm{E} 2 \% 80 \% 99$ s-business-models-andsupply-chains [accessed September 2018].

Anner, Mark (2019) Squeezing Workers' Rights in Global Supply Chains: Purchasing Practices in the Bangladesh Garment Export Sector in Comparative Perspective. Review of International Political Economy, 27(2): 320-347.

Applebaum, Richard and Gary Gereffi (1994) Power and Profits in the Apparel Value Chain. In Global Production: The Apparel Industry in the Pacific Rim, edited by Edna Bonacich, Lucie Cheng, Norma Chinchilla, Norma Hamilton and Paul Ong. Philadelphia, PA: Temple University Press.

Baldwin, Richard (2016) The Great Convergence. Cambridge, MA: Harvard University Press.

Barrientos, Stephanie (2014) Gendered Production Networks: Analysis of Cocoa-Chocolate Sourcing. Regional Studies, 48(5): 791-903.

Bhattacharjee, Anannya and Ashim Roy (2016) Bargaining in Garment GVCs: The Asia Floor Wage. In Labour in Global Value Chains in Asia, edited by Dev Nathan, Meenu Tewari and Sandip Sarkar. 
Cambridge: Cambridge University Press.

Chan, Jenny, Pun Ngai and Mark Selden (2016) The Politics of Global Production: Apple, Foxconn and China's New Working Class. In Labour in Global Value Chains in Asia, edited by Dev Nathan, Meenu Tewari and Sandip Sarkar. Cambridge: Cambridge University Press.

csimarket.com (2019) Levi Strauss \& Co.'s Gross Profit Margin (Quarterly). https://csimarket.com/ stocks/singleProfitabilityRatios.php? code=IVISF\&gro [accessed 15 January 2019].

Degain, Christophe, Bo Meng and Zhi Wang (2017) Recent Trends in Global Trade and Global Value Chains. In Global Value Chain Development Report 2017: Measuring and Analyzing the Impact of GVCs on Economic Development. Washington, DC: The World Bank.

Dobbelaere, S. (2005) Joint Estimation for Price Cost Margins and Union Bargaining Power for Belgian Manufacturing. IZA Discussion Paper 1466. https://papers.ssrn.com/so13/papers.cfm?abstract id $=572851$ [accessed 13 May 2020].

Durand, Cedric and William Milberg (2019) Intellectual Monopoly in Global Value Chains. Review of International Political Economy, 27(2): 404-429.

Ernst, Dieter (2012) Production and Innovation Networks, Global. Encyclopedia of Global Studies. Thousand Oaks, CA: Sage Knowledge.

Evers, Barbara, Flavia Amoding and Aarti Krishnan (2014) Social and Economic Upgrading in Floriculture Global Value Chains: Flowers and Cuttings GVCs in Uganda. Capturing the Gains Working Paper 2014/42. http://www.capturingthegains.org/publications/workingpapers [accessed 13 May 2020]

Fang, Cai and M. Wang (2010) Growth and Structural Changes in Employment in Transition China. Journal of Development Economics, 38: 71-81.

Gereffi, Gary, John Humphrey and Timothy Sturgeon (2005) The Governance of Global Value Chains. Review of International Political Economy, 12(1): 78-104.

Holdcroft, Jenny. 2015. "Transforming Supply Chain Industrial Relations." International Journal of Labour Research, 7(1-2): 95-104.

Ichinowski, C. and K. Shaw (2003) Beyond Incentive Pay: Insiders' Estimates of the Value of Contemporary Resource Management Practices. Journal of Economic Perspectives, 17(1): 155-80.

Kalecki, Michal (1971) Class Struggle and the Distribution of National Income. In Selected Essays in the Dynamics of the Capitalist Economy, 1933-1970. Cambridge: Cambridge University Press.

Kaplinsky, Raphael (2019) Rents and Inequality in Global Value Chains. In Handbook of Global Value Chains, edited by Gary Gereffi, Stephano Ponte and Gale Raj-Reichert. London: Edward Elgar.

Kelkar, Govind, Girija Shrestha and N. Veena (2002). Women's Agency and the IT Industry in India. Gender, Technology and Development, 6(1): 63-84.

Kumar, Ashok (2020) Monopsony Capitalism: Power and Production in the Twilight of the Sweatshop Age. Cambridge: Cambridge University Press.

Lakhani, T., S. Kuruvilla and A. Avgar (2013) From the Firm to the Network; Global Value Chains and Employment Relations. British Journal of Industrial Relations, 51(3): 440-472.

Lan, Tu and John Pickles (2011) China's New Contract Labour Law: State Regulation and Worker Rights in Global Production Networks. Capturing the Gains Working Paper 2011/05. http://www.capturingthegains.org/ publications/workingpapers [accessed 13 May 2020].

Lewis, Arthur (1954) Economic Development with Unlimited Supplies of Labour. The Manchester School, 22(2): 139-191.

Miller, Doug (2013) Towards Sustainable Labour Costing in UK Fashion Retail. Capturing the Gains Working Paper. http://www.capturingthegains.org/publications/workingpapers [accessed 13 May 2020].

Mishel, L. (1986) The Structural Determinants of Union Bargaining Power. Industrial Labour Relations Review, 
40(1): 90-104.

Murthy, Narayana (2009) A Better India, A Better World. New Delhi: Penguin Books.

Nathan, Dev (2016) Governance Types and Employment Systems. In Labour in Global V alue Chains in Asia, edited by Dev Nathan, Meenu Tewari and Sandip Sarkar. Cambridge: Cambridge University Press.

Nathan, Dev and Sandip Sarkar (2010) Blood on Your Mobile? Economic and Political Weekly, 45(43): 22-24.

Nathan, Dev and Sandip Sarkar (2011) Profits, Rents and Wages. Economic and Political Weekly, 46(36): 5357.

Nathan, Dev, Madhuri Saripalle and L. Gurunathan (2016) Labour Practices in India. ILO Asia-Pacific Working Papers. Bangkok: International Labour Organization.

Nathan, Dev, Meenu Tewari and Sandip Sarkar (eds.) (2016) Labour in Global Value Chains in Asia. Cambridge: Cambridge University Press.

Nathan, Dev, S. Rahul, Purushottam Kumar and Shikha Silliman Bhattacharjee (2020, forthcoming) Subsidies in Global Production: A Study of the Indian Garment Industry. Cambridge: Cambridge University Press.

Neilson, J. and B. Pritchard (2009) Value Chain Struggles: Institutions and Governance in the Plantation Districts of South India. London: Wiley Blackwell.

Noronha, Ernesto and Premilla D'Cruz (2016) Still a Distance to Go: Social Upgrading in the Indian ITOBPO-KPO Sector. In Labour in Global Value Chains in Asia, edited by Dev Nathan, Meenu Tewari and Sandip Sarkar. Cambridge: Cambridge University Press.

Pagano, Ugo (2014) The Crisis of Intellectual Monopoly Capitalism. Cambridge Journal of Economics, 38: 1409_ 1429.

Pal, Rupayan and Udayan Rathore (2014) Estimating Workers' Bargaining Power and Firms' Mark-up in India. Paper Presented at ISLE Conference, Ranchi, India, 18-20 December. Mimeo.

Pani, Narender and Nikky Singh (2014) Women at the Threshold of Globalization: Garment Workers in Bangalore. New Delhi: Routledge.

Prahalad, C.K. and G. Hamel (1990) The Core Competence of the Corporation. Harvard Business Review, 68(3): 79-91.

Raj-Reichert, Gale (2018) The Changing Landscape of Contract Manufacturers in the Electronics Industry Global Value Chain. In Development with Global V alue Chains: Upgrading and Innovation in Asia, edited by Dev Nathan, Meenu Tewari and Sandip Sarkar. Cambridge: Cambridge University Press.

Sachitanand, Rahul (2018) Why Indian IT Firms are Hiring Teams Overseas. The Economic Times, 23 December 2018.

Samel, Hiram (2012) Upgrading under Volatility in a Global Economy. MIT Sloan School of Management. http://sstn.com/abstract+2102643 [accessed 9 December 2014].

Sarkar, Sandip and Balwant Singh Mehta (2016) What Do Workers Gain from Being in a GVC? ICT in India. In Labour in Global Value Chains in Asia, edited by Dev Nathan, Meenu Tewari and Sandip Sarkar. Cambridge: Cambridge University Press.

Sarkar, Sandip, Balwant Mehta and Dev Nathan (2013) How Social Upgrading Drives Economic Upgrading by Indian IT Majors. Capturing the Gains Working Paper No. 27. http://www.capturingthegains.org/ publications/workingpapers [accessed 25 July 2015].

Shih, Stan (2010) Millennium Transformation: Change Management for New Acer. Translated by Eugene Hwang. Aspire Academy Series. http://www.stanshares.com.tw/StanShares/upload/tbBook/1 2010081714 4639.pdf [accessed 4 July 2017].

Silver, Beverley (2003) Forces of Labor: Workers' Movement and Globalization since 1870. Cambridge: Cambridge University Press.

Statistica (2019) Market Share of Leading Chocolate Companies Worldwide in 2016. https:/ /www.statista.com/statistics/629534/market-share-leading-chocolate-companies-worldwide 
[accessed 4 March 2020].

Statistica (2020) Market Share of the Leading Coffee Chains in the United States as of October 2019, by Number of Outlets. https://www.statista.com/statistics/250166/market-share-of-major-us-coffeeshops [accessed 4 March 2020].

\section{ACKNOWLEDGEMENTS}

Thanks to Neetu Ahmed, Balwant Mehta, Purushottam Kumar and S. Rahul for research support at different times. Thanks also to two anonymous reviewers and, particularly, to the editors of the Global Labour Journal for comments and questions that helped improve the paper. The responsibility for analysis and any errors is that of the author alone.

\section{BIOGRAPHICAL NOTE}

Dev NATHAn is Research Advisor, Society for Labour and Development, Delhi; Visiting Professor, Institute for Human Development, Delhi; and Research Director, GenDev Centre for Research and Innovation, Gurgaon. [Email: nathandev@hotmail.com] 